University of Montana

ScholarWorks at University of Montana

Fall 1991

\title{
William Blake and the Language of Adam by Robert N. Essick
}

James C. McKusick

University of Montana - Missoula, mckusickj@umkc.edu

Follow this and additional works at: https://scholarworks.umt.edu/eng_pubs

Part of the English Language and Literature Commons

Let us know how access to this document benefits you.

\section{Recommended Citation}

McKusick, James C., "William Blake and the Language of Adam by Robert N. Essick" (1991). English Faculty Publications. 10.

https://scholarworks.umt.edu/eng_pubs/10

This Book Review is brought to you for free and open access by the English at ScholarWorks at University of Montana. It has been accepted for inclusion in English Faculty Publications by an authorized administrator of ScholarWorks at University of Montana. For more information, please contact scholarworks@mso.umt.edu. 


\section{Book Reviews}

William Blake and the Language of Adam

by Robert N. Essick

Oxford: Clarendon Press, 1989. $x+272$ pages. $\$ 62.00$.

\section{Reviewed by James C. McKusick}

Several recent studies have examined the role of linguistic theory in Romantic poetry and poetics. Notable among these are Shelley's Style by William Keach (1984) and Verbal Imagination: Coleridge and the Language of Modern Criticism by A. C. Goodson (1988). Both of these studies trace the complex intellectual background of their chosen poet's linguistic theories and examine how these theories are formally exemplified and problematized in particular poems. Coleridge and Shelley seem especially appropriate as subjects for this type of investigation, since they both attended elite universities, were voracious readers of literature and philosophy, and left ample records of their multifarious intellectual interests. It is relatively easy to demonstrate their participation in the dominant Western tradition of philosophical speculation on the origin and structure of language, extending from Plato and Aristotle through the British empirical philosophers Locke, Berkeley, Hume, and Hartley, and their French and German contemporaries: Descartes, Condillac, Rousseau, Leibniz, Herder, and Humboldt. Both Coleridge and Shelley were well-read in the works of these philosophers, and their ever-evolving responses to the controversial issues of linguistic theory are fully recorded in their letters, notebooks, and marginalia.

William Blake, however, poses a challenging problem for this kind of study, since he lacked a university education, was quirky and unconventional in his reading habits, possessed quite a limited grasp of languages other than English, and left only intermittent and oblique records of his 


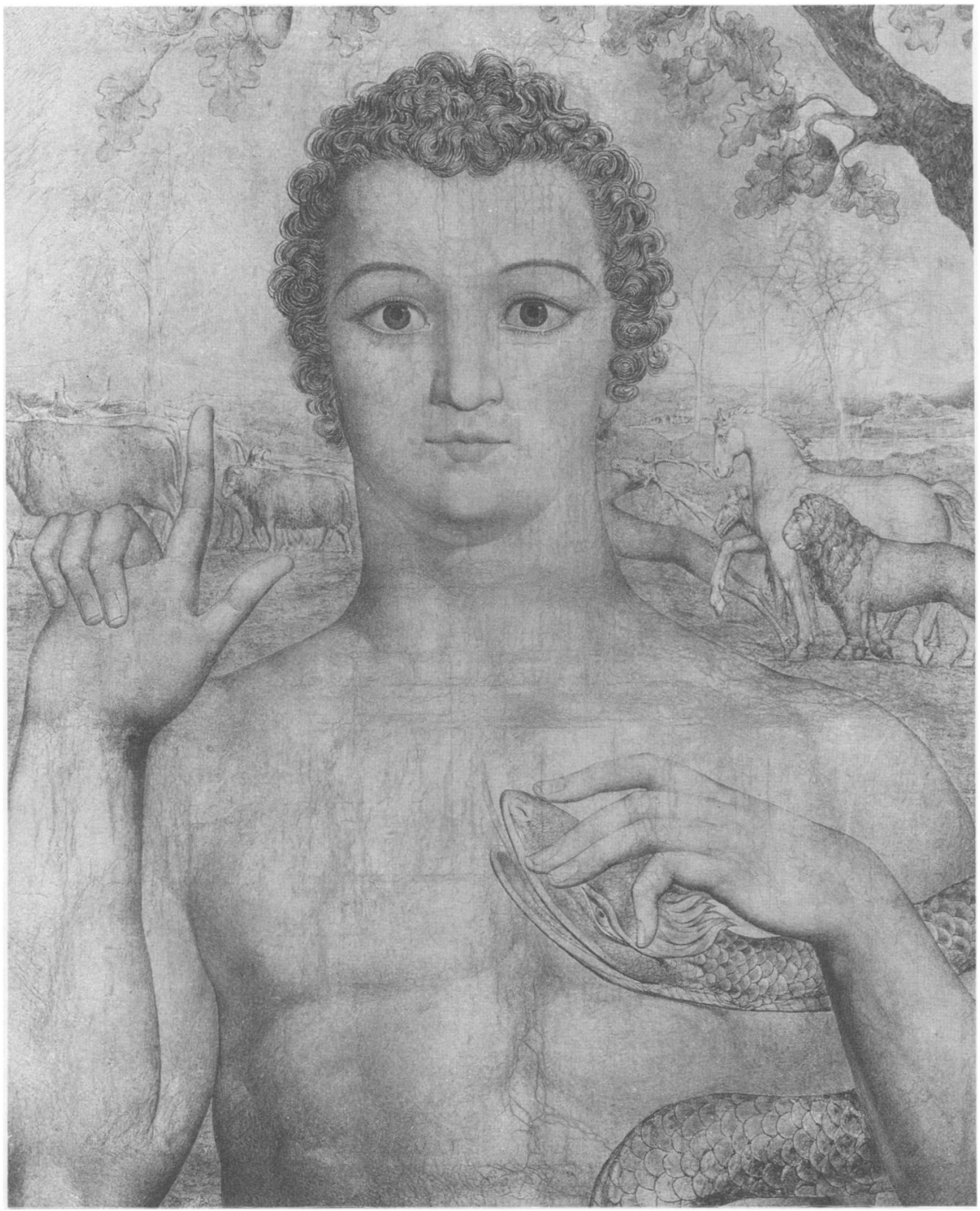

Figure 1: William Blake, Adam Naming the Beasts (courtesy of Glasgow Museums, Pollok House) 
intellectual interests. Given these scanty and unpromising materials, how is it possible to determine Blake's attitude toward the perennial questions concerning the origin and structure of language? Robert Essick has tackled this seemingly intractable subject with characteristic vigor and remarkable success, persuasively demonstrating Blake's engagement in the key linguistic controversies of his own time and clearly indicating the relevance of those debates to the actual mode of production of Blake's illuminated books. William Blake and the Language of Adam is a welcome addition to our knowledge of the Romantic preoccupation with the mystery of linguistic origins, and it seems destined to become a model of bold, incisive, and carefully researched scholarly analysis of literary and artistic creation from a broad interdisciplinary perspective. Essick's impeccable command of Blake's poetry and visual art is complemented by an extensive knowledge of the history of linguistics and an open-minded (yet critical) understanding of current issues in semiotics, phenomenology, and post-structuralist literary theory. William Blake and the Language of Adam provides an important addition to our knowledge of Blake's linguistic practice and offers a provocative challenge to the widespread post-structuralist conception of language as a differential system.

In order to establish a frame of reference for the competing ideologies of language exemplified throughout Blake's poetry and graphic art, Essick examines a series of four tempera paintings produced by Blake at roughly the midpoint of his professional career as an artist and engraver (c. 1810). The first of these paintings, Adam Naming the Beasts, depicts Adam raising his right hand with the index finger extended, while various animals troop past in the background, thus representing the original human act of linguistic creation. Adam's raised-finger gesture is a traditional iconographic image normally used to indicate that the subject is speaking, as Essick demonstrates by reference to a variety of illuminated and illustrated works, including two remarkable eighteenth-century engravings from the extra-illustrated Kitto Bible (a unique compilation of Bible illustrations in the Huntington Library collection). These two engravings, both depicting a rather diminutive Adam surrounded by numerous animals, serve to characterize the graphic precursors of Blake's image while also showing how radically Blake diverges from the mainstream of Bible illustration. Blake's Adam looms much larger in the foreground than he does in these earlier engravings, thus suggesting the prominence of human agency in Blake's conception of linguistic origins. According to Essick, "Blake's painting reveals an Adam-cum-Godlike poet bestowing upon the beasts the names, the mental forms, from which they originated in the Mind of God and through which they take on their being for man" (12). Essick concludes that this conception of 
Adamic naming entails a constitutive understanding of language, not unlike that of Wilhelm von Humboldt or Martin Heidegger, in which words provide a medium of existence for the things they signify.

Also quite prominent in Blake's painting of Adam Naming the Beasts, however, is the disturbing figure of the serpent cradled in Adam's left arm. As Essick points out, "even if we think of the snake as still benign and unalloyed with Satan, it is impossible to avoid prolepsis" (14). The presence of the serpent tends to darken Blake's image of Adamic naming and to imply an alternative conception of language in which the imposition of words upon things entails a fall into abstraction. Rather than actively participating in the being of the things they signify, these Adamic names might simply impose arbitrary taxonomic categories upon them, thus enacting "a descent from Logos to logic" (15) and creating an ineluctable gap between meaning and being. "If this is the nature of the language brought into the world by Adam, then his Eden has already fallen under the dominion of Urizen, Blake's creator of bondage, abstraction, generalization, law, the indefinite, the void" (15). Essick further aligns this rather pessimistic view of Adamic naming with a conception of language common to Friedrich Nietzsche, Jean-Paul Sartre, and Jacques Derrida, all of whom regard signs as "radically different in their matter and form from the things to which they refer" (15-16). This differential conception of language, while not entirely superseding the more positive conception previously discussed, nevertheless accompanies it as a dark double throughout the rest of Essick's study. Just as Blake's painting of Adam Naming the Beasts is susceptible of two opposing interpretations, Essick will argue in later chapters that Blake's major prophetic books invite readings that entail alternative conceptions of the nature of semiosis.

Essick derives further possible conceptions of language from the remaining paintings in this series. Eve Naming [or Listening to] the Birds depicts Eve with her hands raised in a gesture of surprise, perhaps implying an imitative or expressive conception of linguistic origin. The Virgin and Child in Egypt likewise depicts the Madonna with upraised hands, although subtle differences from the gesture and posture of Eve tend to emphasize her reverence and veneration for the Christ child shown in her lap. The background of this painting, with its depiction of typical Egyptian architecture, evokes the fallen world of materialism, slavery, and death, while the traditional association of Egypt with hieroglyphic writing might also suggest to Blake a fallen form of language, a mysterious priestly code. The Christ child provides a dramatic contrast to this Egyptian setting, exemplifying what Essick terms an "incarnational sign - that is, a sign which is one with its referent" (24). The final painting, Christ Blessing, depicts Christ's right hand upraised with the 


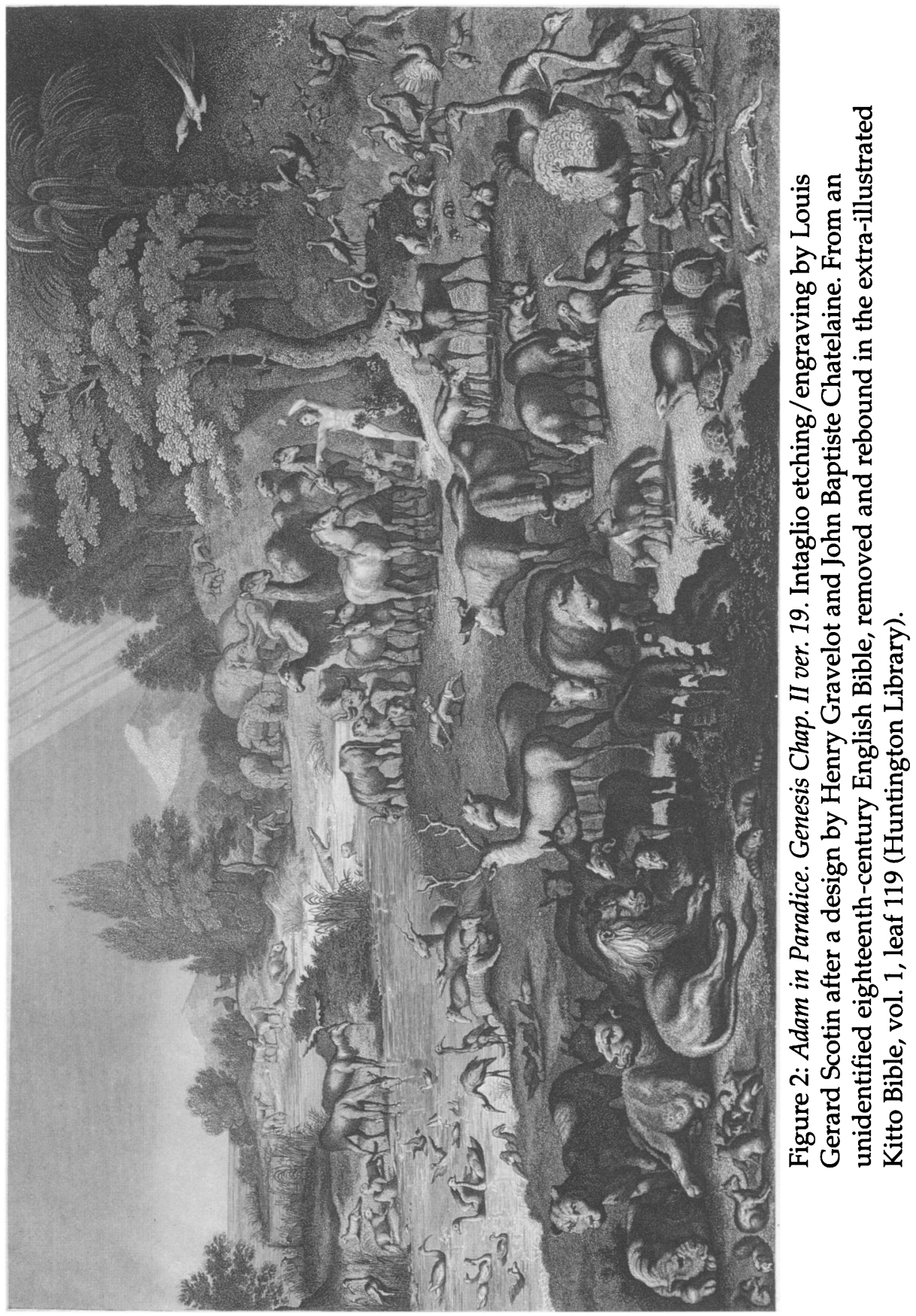




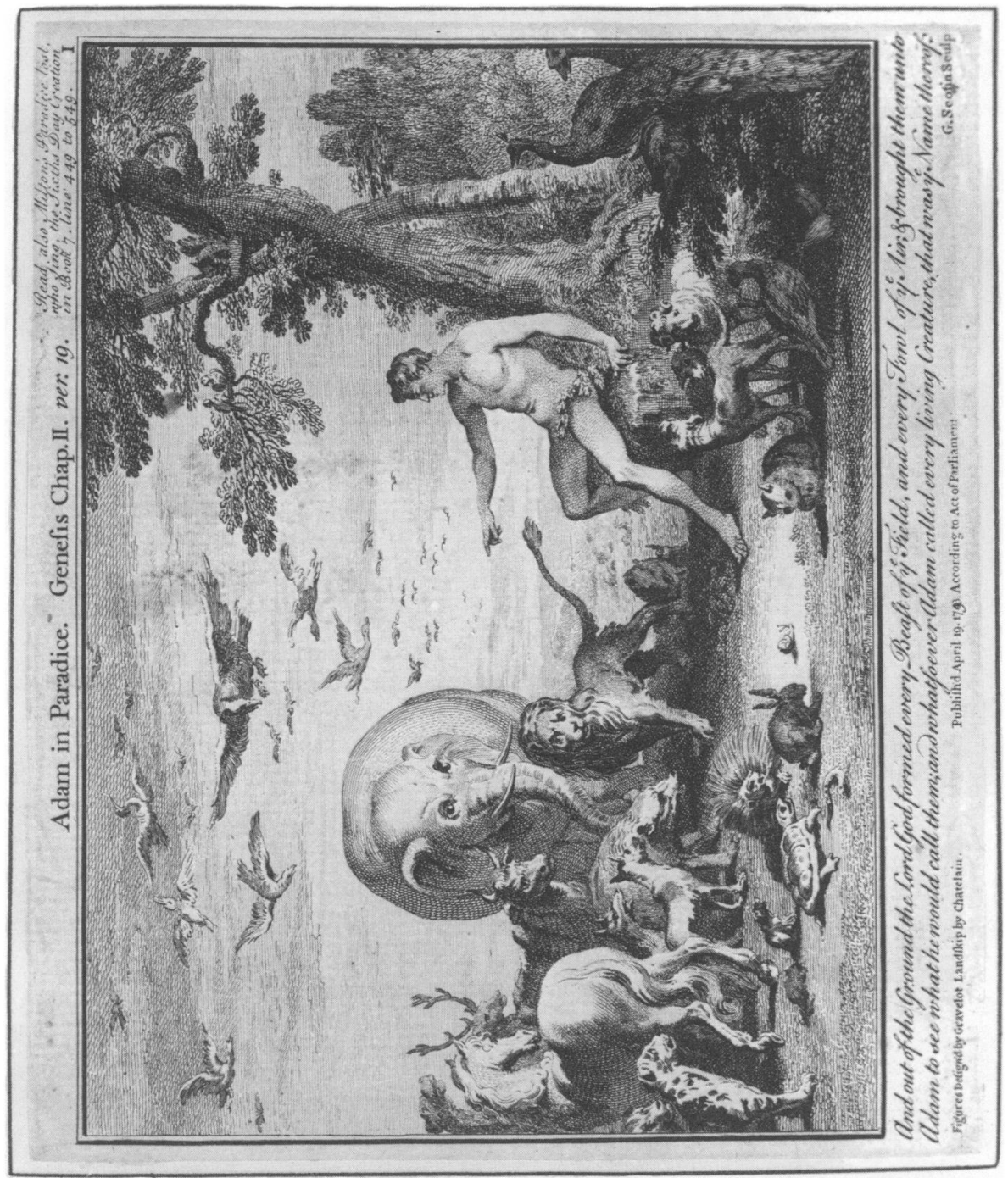

Figure 3: Adam Naming the Creation. Published 20 September 1817 by Thomas Kelly, London. Intaglio etching/engraving based on a print by the Dutch artist Jan Luiken (1649-1712) From the extra-illustrated Kitto Bible, vol. 1, leaf 115 (Huntington Library). 
palm turned outward in a conventional gesture of blessing. Unlike the previous paintings in this series, Blake's final representation of the act of blessing requires for its completion the sympathetic response of the recipient, or believer. By thus engaging the recipient of this "kerygmatic" or performative gesture, Blake invokes a concept of semiosis that is essentially triadic, supplementing the duality of the signifier/signified with a third entity, the recipient. In Essick's view, this triadic conception of the linguistic sign offers a way out of the barren confrontation of positive and differential views of language, since it promises to reconcile these conflicting paradigms by engaging the recipient (or reader) as an active participant in the process of creating meaning.

Having established these alternative conceptions of the linguistic sign as a frame of critical reference, Essick turns to a more detailed historical survey of the tradition of philosophical speculation on the origin and structure of language. He devotes particular attention to those theories likely to have been known to Blake, but he does not narrowly confine himself to source-and-influence hunting. Essick's intention, rather, is "to delineate the landscape of intellectual possibilities available in [Blake's] age" (27). This is the topic of the book's longest and most intricate chapter, "In Pursuit of the Motivated Sign." Essick surveys the interpretive history of the biblical description of Adam naming the beasts and the confusion of tongues at Babel, showing how these accounts gave rise to a persistent belief in a lost Adamic tongue that was somehow more "natural" than any existing language. During the seventeenth century this belief inspired the production of various artificial-language schemes which would, in the words of John Webster, repair "the ruines of Babell" (39) and thus make universal communication possible. These artificiallanguage projectors, such as Cave Beck, George Dalgarno, and John Wilkins, sought to recreate in a modern writing system the supposed attributes of the original Adamic language, particularly the "real" or motivated relationship of each sign to its referent. In practice, however, these language projectors managed to create nothing more than a confusing array of arbitrary signs, dividing up the world into abstract logical categories. A taxonomic approach to human knowledge is also apparent in the philosophy of John Locke, who adopts a "sensibilist" theory of reference, arguing that words have a merely arbitrary relation to ideas, which are derived primarily from sensible objects.

Blake responded scornfully to such Urizenic theories of language, denouncing "Lockes Opinions of Words" as totally "Fallacious" (46). Essick explains that Blake rejected "the sensibilist position that limits words to object-reference" (46). Blake found himself in much closer sympathy with a mystical tradition of linguistic speculation that extends from Robert Fludd through Jacob Boehme and Emanuel Swedenborg. 
Blake was especially attracted to Boehme's belief that fallen human languages (such as English and German) still contain traces of the lost Adamic tongue. In Boehme's view, these traces of the original "Language of Nature" (49) can be discovered through a rather arcane method of phonemic analysis. Essick argues that Boehme, like Blake, is a "linguistic materialist, in spite of his obvious dedication to transcendental meanings" (52), since both seek to discover a spiritual significance in the concrete details of particular words and sounds. Another important source of sympathy between Blake and Boehme (not mentioned by Essick) was their common social identity as self-educated artisans, which would have led Blake to admire and emulate Boehme's prophetic religious vocation, and perhaps also to accept Boehme's view that modern vernacular languages (not Greek or Hebrew) were the most promising terrain for the discovery of the original Adamic tongue.

Essick proceeds to examine the linguistic implications of Blake's engagement in contemporary politics, focusing especially on the controversial figure of John Horne Tooke. A friend of Thomas Paine and a member of the London Constitutional Society, Tooke was deeply involved with the radical democratic circles that Blake frequented during the early 1790s, and Essick suggests that Tooke is a likely source for some of Blake's most radical linguistic ideas. Blake would have been profoundly receptive to Tooke's use of etymology to demystify the pretentious illusions of the ruling class, and he would certainly have admired Tooke's devastating critique of abstraction, although he would not have accepted Tooke's essentially Lockean epistemology and his consequent habit of tracing all words back to their supposed origin in sense-impressions. Nevertheless, Essick argues that Blake's poetic use of etymology is almost certainly indebted to Tooke, particularly his formation of proper names and his multivalent use of key words (such as charter'd and mark in the poem "London"). Essick's sustained analysis of the relation between linguistics and politics in Blake's poetry is one of the most innovative features of his book, although more work still remains to be done on this topic. David Erdman's classic study, Blake: Prophet against Empire (1954), together with Michael Ferber's The Social Vision of William Blake (1985), provide a reliable guide to Blake's evolving political views, but without much attention to his engagement in contemporary linguistic theory. Blake's ideological deployment of language needs to be more fully examined, both in his overtly political poems, such as America and The French Revolution, and in his major prophetic books, Milton and Jerusalem.

Having authoritatively situated Blake in the history of linguistic theory, Essick describes how these theories are internalized, and often implicitly criticized or parodied, in Blake's poetry. Essick's brilliant close readings 
of the shorter lyric poems will be of particular interest to teachers of Blake, since his demonstration of their engagement in linguistic controversy should be accessible to advanced undergraduates. Examining the auditory linguistic signs that pervade the Songs of Innocence, Essick argues that these poems aspire to the spontaneity of oral-formulaic composition, as described by such eighteenth-century theorists as Thomas Blackwell and Robert Lowth, and supposedly exemplified in Homeric epic and the "primitive" poetry of Ossian. Drawing upon this tradition, the Songs of Innocence seek to reconstitute an unfallen state of language through the self-sufficiency of the incarnational sign. In "The Lamb," for instance, "Blake's use of natural signs derives its innocence, its Adamic character, through the presence of the new Adam as the implied referent throughout the language of innocence" (113).

In contrast, the Songs of Experience represent a fallen state of language, since they often foreground their ontological status as written texts divorced from the act of linguistic creation, and are thus "self-consciously aware of the differential nature of language" (128). In "The Tyger," for example, the speaker is revealed as an "idiot Questioner" trapped in the differential system of taxonomic logic; and "the domination of the figural by the logical results in their mutual distortion" (130). In "London," similarly, "taxonomic and grammatical structures take their own domain as the essence of language" (137), thereby transforming real human suffering into abstract "marks of weakness, marks of woe" (135). The poem enacts this semiotic reduction, in Essick's view, while also exposing the harsh ideological implications of differential sign-systems, which tend to validate the status quo and subjugate the common people with "mindforg'd manacles" (136). Essick further elucidates Blake's critique of semiosis in a detailed reading of The Book of Urizen, which he regards as a mythic account of the fall of language from divine plenitude into differential obscurity.

Blake did not allow himself to be trapped by this fallen sense of language as a "devouring structure" (159); and in a chapter entitled "Language and Modes of Production," Essick examines an alternative conception of language as a "prolific activity" (159) that Blake enacted in his own compositional practice. Bringing to bear the detailed knowledge of Blake's printing methods that he established in his still-definitive study, William Blake, Printmaker (1980), Essick describes the role of accident or "error" in Blake's printmaking, showing that Blake incorporated all sorts of variants, whether "intentional" or not, at various stages in the production of his illuminated books. Rejecting the standardization required of most professional engravers, Blake allowed each impression to take on its own distinctive character in matters of reticulation, density, and coloration. Essick argues that Blake's "willingness to incorporate the 
contingent" (191) also extends to his verbal production. Blake rejected the standardization of grammar, orthography, and punctuation that had attained hegemonic status during the eighteenth century; and his prophetic books, with their flamboyantly nonstandard language, inscrutable proper names, and rhetorical mode of punctuation, vividly exemplify Blake's idiosyncratic sense of language as "Living Form" (193). Essick concludes that "by embracing the accidental as part of textual production, the poet gains access to the dynamic of language evolution" (194). In order to surmount the taxonomic conception of language as a static system, Blake rediscovers his own role as an active participant in the making of "English, the rough basement" (Jerusalem, plate 36). This generative conception of language is more fully developed in the book's final chapter, "The Return to Logos."

More than just a sweeping historical survey, or a pedestrian study of sources and influences, William Blake and the Language of Adam carves out a distinct theoretical niche for itself, examining Blake's poetry and graphic art from a boldly original theoretical point of view. In a brief "Afterword: Romantic Languages and Modern Methodologies," Essick takes direct aim at the ubiquitous modern understanding of language as a differential system, exemplified in the work of Ferdinand de Saussure and still pervasive among such post-structuralist theorists as Jacques Derrida. Essick argues that "the universality of this method is its greatest limitation, for it fails to discriminate among the different ways texts respond to different conceptions of language" (238). Although the poststructuralist conception of language can provide valuable insights into Blake's essentially negative, skeptical, and ironic stance in such texts as The Book of Urizen, it nevertheless remains a "synchronic reduction" (238) that blinds its practitioners to the more positive, self-confident, and generative conception of language that governs a text like Jerusalem. In Essick's view, "When such texts engage transcendence as a product of linguistic performance, they do so not to deconstruct the transcendental but to celebrate the engendering powers of language" (239).

This constitutive understanding of language, following in the tradition of Boehme, Humboldt, and Heidegger, promises to restore "the historicity of language itself" (238) by allowing the modern reader of Blake's illuminated books to participate, if only vicariously, in the act of textual production, despite the widening temporal gap that separates Blake's historical moment from our own. Blake's unique combination of verbal and visual art in his prophetic books would seem to provide an ideal test case for this constitutive theory of language, since the rough, unfinished texture of these books, as well as Blake's endless tinkering with the appearance, content, and order of their engraved plates, tends to foreground the act of textual production and thus to encourage the reader's 
active involvement in the generation of meaning. Although one might quibble with the notion of "historicity" advanced here (on the grounds that it seems insufficiently concrete in its analysis of the political, social, and ideological determinants of linguistic practice), there is no denying the force of Essick's critique of deconstructionist dogma and his corresponding celebration of Blake's "apocalyptic quest through the diachronic activities of the linguistic mind" (238-39). Addressed not only to Blake scholars, but to questing readers of all sorts, William Blake and the Language of Adam provides a fresh, engaging, and persuasive account of Blake's evolving attitudes toward language.

University of Maryland, Baltimore County

Intellectual Culture in Elizabethan and Jacobean England:

The Latin Writings of the Age

by J. W. Binns.

Wiltshire, England: ARCA, 1990. xxv + 761 pages.

Reviewed by John Mulryan

This astonishingly ambitious book attempts both to survey the Latinate culture of Renaissance England and to emphasize its profund influence (for the most part ignored by modern scholars) on all phases of life and thought during this period. With an almost messianic fervor and indefatigable vigor Professor Binns catalogues and comments upon a huge mass of literature on almost every conceivable subject: poetry, fiction, drama, literary criticism, theology, politics, physical science, history, philosophy, law, biography, printing, translation, grammar, rhetoric, education. Professor Binns worked his way through this enormous canon (listed in Pollard and Redgrave's Short-Title Catalogue for the period) by using microfilms, which he found very useful whenever he "needed to check some minor point in perhaps thirty-five different books" (xix). Microfilm also enabled him to cover huge batches of material without dawdling about: "Every six months or so another batch of forty reels containing several hundred items would arrive, and if I wanted to see an item that had not been filmed, I usually found it perfectly possible to wait until it was available, since there was after all no shortage of material waiting to be read" (xix). Still, even Professor Binns has his limitations, and the scope of the book was finally limited to selected Latin works published in England between 1530 and 1640:

I started my programme of reading with the aim of looking at every page of every Latin book printed in England up to 1640. Of 